\title{
Especialização esportiva precoce e o ensino dos jogos coletivos de invasão
}

\author{
Rafael Pombo Menezes* \\ Renato Francisco Rodrigues Marques** \\ Myrian Nunomura***
}

\begin{abstract}
Resumo: O objetivo deste artigo foi estabelecer uma relação entre diferentes princípios metodológicos de ensino dos jogos coletivos de invasão $(\mathrm{JCl})$ e processos de especialização esportiva precoce (EEP). Considerou-se EEP como um fenômeno proveniente da imposição a crianças, de regimes de competição e treinamento voltados para o rendimento a adultos e à especificidade e limitação de experiências motoras. Apoiados na literatura, concluímos que o ensino de $\mathrm{JCl}$ não influencia diretamente o processo competitivo na iniciação esportiva desde que apresente variedade de métodos e seja pautado em práticas de modalidades diferentes, o que evitaria ações estereotipadas e, assim, não estimularia a EEP.

Palavras-chave: esportes. Especialização. Intervenção precoce.
\end{abstract}

\section{INTRODUÇÃo}

Os Jogos Esportivos Coletivos (JEC) são compostos por elementos técnicos e táticos (individuais e coletivos) específicos, sendo que a combinação desses conteúdos resulta na complexidade do jogo, no qual os aprendizes são os principais protagonistas. Tratase, ainda, de "um microsistema social complexo e dinâmico" (GARGANTA, 1998, p.15), em que as relações existentes dentro de um grupo não podem ser representadas pela soma dos valores e talentos individuais (MENEZES, 2012).

\footnotetext{
"Professor, Escola de Educação Física e Esporte de Ribeirão Preto (EEFERP), Universidade de São Paulo (USP), Ribeirão Preto, SP, Brasil. E-mail: rafaelpombo@usp.br

"Professor, Escola de Educação Física e Esporte de Ribeirão Preto (EEFERP), Universidade de São Paulo (USP), Ribeirão Preto, SP, Brasil. E-mail: renatomarques@usp.br

"'*Professor, Escola de Educação Física e Esporte de Ribeirão Preto (EEFERP), Universidade de São Paulo (USP), Ribeirão Preto, SP, Brasil. E-mail: mnunomur@usp.br
} 
Ainda sobre as características dos JEC, esses apresentam uma grande quantidade de combinações de movimentos (simultâneas ou sucessivas) e ações que são concebidas coletivamente ou em grupos menores (TAVARES, 1996). Outros fatores relevantes dos JEC são a variabilidade das situações de jogo, a velocidade com que as informações devem ser processadas (a partir da percepção do ambiente), a coerência para as tomadas de decisões, a velocidade na execução das ações motoras e a complexidade e imprevisibilidade provocada pela combinação desses fatores (GRECO, 1988; TAVARES, 1996; PAULA; GRECO; SOUZA, 2000; MENEZES, 2012).

Os Jogos Coletivos de Invasão (JCI) são formas de JEC que se caracterizam pelo confronto entre atacantes e defensores, em um espaço comum com ações simultâneas entre os sujeitos oponentes. Nos JCI a bola (ou algum outro implemento) é tida como referência e objeto de posse (REVERDITO; SCAGLIA, 2009), e englobam modalidades como o basquetebol, o handebol, o futsal e o futebol.

Os JEC despertam o interesse de pesquisadores de diferentes áreas que buscam compreender possíveis variáveis que expliquem seus fenômenos. Além disso, atraem o interesse de bilhões de telespectadores ao redor do mundo, seja com olhares críticos ou de admiração por esse fenômeno. Não obstante, crianças e jovens aumentam o interesse pela prática dos JEC por fatores como o prazer em participar ou ainda como uma forma de ascensão social. Tal participação agrega aos processos de ensino-aprendizagemtreinamento (EAT) certa responsabilidade frente à promoção de desenvolvimento moral de crianças e jovens (COAKLEY, 2008), além da inserção do esporte como uma prática cotidiana em suas vidas, até a idade adulta (FREIRE, 2006).

Assim, este trabalho procura investigar implicações pedagógicas que envolvam os processos de EAT de JEC para crianças e jovens, de modo a propor uma reflexão sobre métodos de ensino e suas relações com a inserção e permanência de praticantes em atividades esportivas. 
O ingresso de crianças e jovens nos JEC implica no início de um processo de EAT, conhecido como iniciação esportiva, e que se refere a uma trajetória pedagógica na qual os indivíduos envolvidos vivenciam diferentes situações em uma atividade esportiva de modo planejado (RAMOS; NEVES, 2008). Dessa forma, as práticas de ensino no processo de EAT devem ser coerentes com aspectos como a idade das crianças e dos jovens, e respeitar as diferenças individuais entre os praticantes, com vistas à educação para a vida em sociedade e ao desenvolvimento de uma mentalidade crítica e consciente (FREIRE, 1994).

Os métodos de ensino dos JEC foram desenvolvidos e fundamentados para contemplar os fatores apresentados anteriormente. Em cada um dos métodos são estabelecidas metas a serem alcançadas, que se baseiam em objetivos específicos, relacionados com o desempenho futuro e cujo pré-requisito seja a compreensão da meta pelo aprendiz (SCHMIDT; WRISBERG, 2001).

Porém, tais métodos podem ser considerados equivocados principalmente quando estão associados a procedimentos pedagógicos que privilegiam a oferta de práticas esportivas especializadas para as quais as crianças não estejam preparadas. E, como consequência, acarretam em prejuízos ao desenvolvimento motor, emocional e moral dos iniciantes (DARIO; BARQUILHA; MARQUES, 2010; MASSA; UEZU; BÖHME, 2010; CAVICHIOLLI et al., 2011).

Um desses possíveis equívocos é a especialização esportiva precoce (EEP), que consiste em uma forma de treinamento que não coaduna com as características da fase maturacional dos praticantes (MARQUES, 2000). Essa prática pedagógica é observada em clubes, escolas de esporte e processos de educação formal, em que são recorrentes as ofertas de programas de treinamento esportivo infantil, que seguem os mesmos parâmetros utilizados com adultos e especializam em modalidades específicas (KNIJNIK; MASSA; FERRETTI, 2008). 
Em linhas gerais, a EEP caracteriza-se como a aplicação de cargas excessivas de treinamento em indivíduos ainda em formação (BARBANTI, 2003), voltadas à especialização em uma modalidade específica. Como definição de EEP, pode-se citar as contribuições de Kunz (1994) e Moesch et al. (2011). O primeiro propõe tal conceituação contextualizada em uma proposta didático-pedagógica da Educação Física baseada na ressignificação de processos de ensino do esporte através de vivências que explorem a problematização e autonomia de crianças frente à prática. $\mathrm{O}$ segundo destaca, em estudo empírico sobre EEP e atletas de alto rendimento, a experiência em apenas uma modalidade como um ponto insuficiente para uma formação esportiva satisfatória:

[...] quando crianças são introduzidas, antes da fase pubertária, a um processo de treinamento planejado e organizado a longo prazo e que se efetiva em um mínimo de três sessões semanais, com o objetivo do gradual aumento do rendimento, além de participação periódica em competições esportivas (KUNZ, 1994, p. 45).

[...] envolvimento precoce em um esporte principal; normalmente ocorre durante a infância, com pequeno ou nenhum envolvimento com outras modalidades (MOESCH et al., 2011, p.282).

A EEP pode ocorrer de diversos modos, de acordo com o sentido adotado para a prática esportiva e os valores morais por ela transmitidos (MARQUES; ALMEIDA; GUTIERREZ, 2007). Assim, a forma como os professores e treinadores abordam e cobram algumas atitudes e desempenho esportivo das crianças, associada aos métodos e ferramentas pedagógicas utilizadas, pode ser questionável quando remontam processos de EEP e potenciais prejuízos futuros à criança. Nota-se, em diversas práticas esportivas, relatos sobre a ocorrência de um processo de EEP (NUNOMURA; PIRES; CARRARA, 2009; CAVICHIOLLI et al., 2011), mesmo com várias indicações na literatura a respeito de seus malefícios (SANTANA, 2005; DARIO; BARQUILHA; MARQUES, 2010; MASSA; UEZU; BÖHME, 2010; CAVICHIOLLI et al., 2011). 
A premissa do presente estudo é que o simples fato de utilizar um método de ensino dos JEC não remeteria, necessariamente, a processos de EEP. Porém, a utilização de diversos princípios metodológicos, associados aos procedimentos específicos adotados pelo professor ou treinador, pode contribuir para o direcionamento das atividades que, eventualmente, produziriam prejuízos aos iniciantes na prática esportiva. Assim, são pertinentes reflexões e discussões teóricas que apontem as possibilidades de utilização dos diferentes métodos de ensino dos JEC, de modo que contribuam para um processo de EAT que promova a autonomia e o desenvolvimento integral dos aprendizes e dificultem o processo de EEP.

O objetivo deste trabalho é apresentar o problema da EEP nos JCI e estabelecer possíveis relações com a concepção do processo de EAT, pautando-se em três princípios metodológicos de ensino dos JEC, apontados como importantes vertentes pedagógicas desse universo esportivo (DIETRICH; DÜRRWÄCHTER; SCHALLER, 1984; GRECO, 1998; GRECO, 2001): o analítico-sintético, o globalfuncional e o situacional com processos cognitivos.

Este trabalho consiste em uma investigação e proposta de reflexão teórica baseadas em análise de literatura, a partir dos seguintes critérios metodológicos: 1- obras com relevância acadêmica (constatada pela recorrência de citações em trabalhos da área), direcionadas à discussão sobre métodos de ensino de JEC; 2- obras que descrevessem e discutissem os princípios metodológicos tidos como mais relevantes pela literatura (GRECO, 2001), de modo a embasar a reflexão proposta; 3- seleção de conteúdos de modo a respeitar o seguinte processo: embasamento filosófico dos métodos, descrição de seus objetivos, principais atividades, vantagens e desvantagens. Cabe destacar que os procedimentos descritos no item 3 respeitaram os dois primeiros.

A primeira etapa deste artigo apresenta as abordagens metodológicas selecionadas, destacando suas características, vantagens e desvantagens. Posteriormente, é estabelecida uma reflexão sobre EEP em relação aos procedimentos e potenciais prejuízos que poderiam causar aos aprendizes. E, em um terceiro 
momento, é desenvolvida uma discussão teórica sobre os procedimentos metodológicos tratados e a ocorrência de EEP em processos de EAT nos JCI.

\section{MÉtodos de ENSINO dos JEC}

Diversos são os métodos de ensino dos JEC que, diante de diferentes concepções de ideias, priorizam (ou facilitam) o acesso a determinados tipos de informações, tais como: Teaching Games for Understanding (Inglaterra); Game Sense (Austrália); Game Concept Approach (Singapura); Tactical Approach (EUA); Tactical Decision Making Approach (França) (GRAÇA; MESQUITA, 2007); Princípios metodológicos analítico-sintético e global-funcional (Alemanha - DIETRICH; DÜRRWÄCHTER; SCHALLER, 1984); Método de ensino situacional com processos cognitivos (Brasil GRECO, 1998).

Para este trabalho, foram escolhidas como objeto de análise abordagens tidas como mais consolidadas e conhecidas no Brasil (GRECO, 2001), sendo elas (DIETRICH; DÜRRW ÄCHTER; SCHALLER, 1984; GRECO, 1998): analítico-sintético, globalfuncional e situacional com processos cognitivos.

\subsection{AnALÍtICO-SINTÉTICO}

O princípio metodológico analítico-sintético (centrado na aprendizagem técnica de modo desvinculado da tática) prioriza o ensino dos elementos técnicos das modalidades, com base na repetição e automatização de movimentos considerados "ideais" (GRECO, 1998). Desse modo, acredita-se que a aprendizagem de elementos técnicos seja um pré-requisito para acessar o jogo formal e, assim, esse jogo seja fragmentado em partes cada vez menores (PAULA; GRECO; SOUZA, 2000). Porém, o domínio técnico apresentado pelo aprendiz não garante o acesso a um jogo de bom nível, pois a técnica está relacionada com o sucesso ou o fracasso 
em uma situação-problema associada a outros fatores, como a condição física e as capacidades de percepção, antecipação e tomada de decisão (GRECO, 1988).

Portanto, considera-se o ensino dos fundamentos de forma repetitiva e descontextualizada das situações-problema do jogo ou, ainda, ensina-se o "como fazer" desvinculado do "quando fazer", "porque fazer" e "onde fazer", o que dificulta a sua compreensão (MENEZES, 2010). Trata-se de um método de repetição exaustiva de movimentos que, diante da premissa do desenvolvimento e aprimoramento técnico, pode desmotivar o aprendiz (GALATTI; PAES, 2007; MENEZES, 2010). Desse modo, esta perspectiva pedagógica baseia-se em atividades fragmentadas e descontextualizadas, as quais priorizam o desenvolvimento do rigor técnico e estereotipado aplicado ao ato motor, independente das situações-problemas do jogo.

Santana (2005) aponta fatores negativos da iniciação esportiva pautada apenas no desenvolvimento de elementos técnicos: a competição como quesito central da avaliação, a reprodução dos modelos do esporte profissional e a tendência à EEP. Dessa forma, Müller et al. (1996) apontam que o rendimento no JEC não deve ser entendido como a soma de resultados dos jogadores da competição em gols, pontos ou passes conseguidos, o que nos apresenta um caráter de complexidade entre as inumeráveis interações entre os jogadores (MENEZES, 2012).

A ruptura com os princípios básicos do método analítico-sintético é um desafio que almeja a formação de aprendizes críticos na resolução de situações-problema de ordem cognitiva, de forma contextualizada, ao invés de apenas reproduzir movimentos. A especialização da criança em elementos técnicos estereotipados e fragmentados, combinada com o ensino baseado na repetição e automatização de movimentos, pode aproximar a criança de padrões motores e comportamentais que tomam como modelo o mundo esportivo do adulto (MARQUES, 2000). Desse modo, o risco reside no fato de que tais aprendizes se especializem em padrões de movimento pré-estipulados que não contribuem, necessariamente, 
para o desenvolvimento da capacidade de resolução de problemas, autonomia e ampliação do repertório motor (DAOLIO; MARQUES, 2003).

\subsection{GLOBAL-FUnCIONAL}

O princípio global-funcional (centrado em jogos) surge com o propósito de promover uma mudança nos paradigmas do ensino de JEC (MEMMERT; HARVEY, 2010). Esse princípio se apóia no processo de EAT que não se restrinja, puramente, ao domínio completo dos elementos técnicos e à automatização desses, mas que desenvolva, concomitantemente, a inteligência dos aprendizes para resolver tarefas cognitivas e motoras.

Memmert e Harvey (2010) apontam que o ensino por meio de jogos ocorre devido a insatisfação frente ao processo centrado nos elementos técnicos, em detrimento da desvalorização dos elementos técnico-táticos (ou dos processos cognitivos relacionados ao jogo). Trata-se, então, de compreender os estímulos como um conjunto organizado (e não fragmentado) (GRECO, 2001), a partir de situações-problema que se baseiam em jogos de menor complexidade, em que os aspectos lúdicos, técnicos, táticos e de regulamento estejam envolvidos (GALATTI; PAES, 2007).

A abordagem global-funcional considera a compreensão da lógica do jogo pelo aprendiz, de forma a ampliar a sua capacidade de assimilação e associação com os demais JEC, a partir da transferência de práticas possíveis entre esses (GALATTI; PAES, 2007). O jogo é tido como um elemento fundamental, no qual a adaptação das regras permite o acesso dos aprendizes aos conteúdos propostos (GALATTI et al., 2008). Esse jogo deve ter seus níveis de dificuldade ajustados de acordo com a compreensão manifestada pelos aprendizes, valorizando o ensino da lógica do próprio jogo, situando o aprendiz e tornando-o apto ao desenvolvimento de novas habilidades (GALATTI; PAES, 2007; MENEZES; SOUSA; BRAGA, 2011).

Assim sendo, tal ruptura proposta pelas correntes cognitivistas e construtivistas com os métodos, que até então eram centrados no 
ensino da técnica, apresentou diferentes possibilidades para o ensino dos JEC. Porém, o fato de deslocar a atenção dedicada às habilidades básicas do jogo para o desenvolvimento da compreensão tática do jogo (GRAÇA; MESQUITA, 2007) apresenta um grande volume de informações ao iniciante, ao passo que desfavorece a relação com a bola em alguns momentos do jogo (SANTANA, 2004).

\subsection{SITUACIONAL COM PROCESSOS COGNITIVOS}

No método situacional com processos cognitivos (GRECO, 1998) (centrado em situações de jogo) o aprendiz deve buscar a inter-relação entre as capacidades técnicas, táticas e cognitivas para solucionar as situações-problema impostas pelo jogo. Esse método baseia-se em situações próprias do jogo formal, desenvolvidas de forma reduzida (como o $1 \times 1$, o $2 \times 1$, o $3 \times 2$, etc.), mantendo os objetivos, princípios e elementos inerentes aojogo formal (MENEZES; SOUSA; BRAGA, 2011).

Nesse método são preconizadas diversas soluções para uma mesma situação-problema (RICCI et al., 2011), sendo que a escolha, pelo aprendiz, de tomar uma ou outra decisão, implicará em diferentes riscos (relacionados a acertos ou erros) e consequentes alterações no cenário técnico-tático do jogo. Considerando as diferentes possibilidades de ação diante de uma situação-problema, espera-se que o aprendiz se posicione criticamente (e inteligentemente) diante de comportamentos imprevisíveis no jogo. Os estudos de Memmert e Harvey (2010) e Ricci et al. (2011) apontam que o ensino por meio de situações de jogo é eficaz para o desenvolvimento do pensamento tático dos aprendizes, e para que esses entendam as razões de seus comportamentos.

Para Greco (2001), é possível desenvolver as capacidades técnicas dos aprendizes concomitantemente ao desenvolvimento das capacidades táticas. Assim, o jogo seria construído a partir da realidade do próprio aprendiz, que gradativamente passaria a compreender e dominar as exigências (físicas, técnicas e táticas) que demandam as situações-problema com as quais se depararia. Dessa forma, nas duas últimas abordagens metodológicas 
apresentadas, há a preocupação de inserir o aprendiz no jogo e nas situações possíveis desse. Essa perspectiva corrobora com Paes (2001), que aponta a importância de se jogar para aprender, contrapondo a premissa de que é necessário aprender (os elementos técnicos) para então jogar.

Ricci et al. (2011) avaliaram (com testes técnicos e táticos) a aprendizagem de jovens no handebol, baseando-se no método situacional. Dentre os três testes de capacidade técnica realizados, dois apresentaram queda de desempenho e um apresentou melhora; em contrapartida, nos quatro testes de capacidade tática houve melhoria de desempenho. Os autores concluíram que, como consequência do método aplicado, os aprendizes apresentaram domínio de um número maior de soluções táticas, aplicando-as com coerência.

Dentre as desvantagens do método situacional, assim como apontadas no método global-funcional, fica evidenciada a ênfase nas questões referentes às tomadas de decisão dos jogadores, em relação ao desenvolvimento técnico, conforme apontado por Ricci et al. (2011). Cabe a ressalva de que diferentes estudos não confirmam a superioridade das abordagens técnicas ou táticas no que se refere à tomada de decisão ou à execução das habilidades no jogo (GRAÇA; MESQUITA, 2007).

\section{CoERÊNCIA ENTRE A TEORIA E A PRÁTICA NO ENSINO dOS JEC}

Diante do exposto, entende-se que as situações-problema que aparentemente possuem resolução simples, estão estreitamente relacionadas à imprevisibilidade que predomina nos JEC. Essa imprevisibilidade decorre de diferentes interações entre os jogadores da mesma equipe e os jogadores adversários.

Garganta (1998) afirma que os JEC são repletos de situações imprevistas, para as quais os jogadores, que têm seus comportamentos regidos por diferentes fatores, devem apresentar respostas táticocognitivas adaptadas às mais diversas configurações. As resoluções 
dessas situações de imprevisibilidade do jogo poderão, muitas vezes, ser condicionadas pelo método adotado pelo professor ou treinador durante as aulas ou sessões de treinamento (MENEZES, 2012). Nos JEC, mais especificamente nos JCI, inúmeras variáveis estão relacionadas em uma mesma situação de jogo, que influenciam os processos de percepção e de tomada de decisão dos jogadores, em que o:

[...] alto nível de incerteza caracteriza, os jogos esportivos coletivos, como esportes de situação; em que não se podem fixar previamente todas as variáveis e parâmetros de rendimento a serem realizados, pois os fatores inerentes ao ambiente interno e externo sempre estão presentes no momento da execução das ações (GRECO; FERREIRA FILHO; SOUZA, 2000, p.123).

Dessa forma, o ensino dos JEC deve pautar-se, entre outros fatores, no desenvolvimento do pensamento tático individual e coletivo crítico, explorado ao longo do processo de EAT, na medida em que os aprendizes entendem as diferentes possibilidades de ação no contexto do jogo. Um método consistente para o ensino dos JCI não deve considerar, portanto, apenas o caráter do desenvolvimento da individualidade e especificidade técnica (manifestada pela execução exímia dos elementos técnicos), mas também a interação entre os jogadores e as respostas às situações-problema.

Faz-se necessário, portanto, refletir sobre a importância do desenvolvimento de diferentes conteúdos de cada JEC para transformar um jogo inicialmente caótico e desorganizado em um ambiente no qual os aprendizes expressem, por exemplo, melhor distribuição espacial e compreensão das situações (ambas relacionadas aos indicativos de jogo de bom nível - GARGANTA, 1998). As capacidades táticas estão relacionadas com três aspectos norteadores: percepção, antecipação e tomada de decisão (GRECO, 1988), e se apresentam como:

[...] pré-requisitos do rendimento, caracterizandose pelo elevado potencial do indivíduo para a aplicação do conhecimento adquirido ao longo do

Movimento, Porto Alegre, v. 20, n. 01, p. 351-373, jan/mar de 2014. 
processo de desenvolvimento da tomada de decisão. Representam a síntese das capacidades perceptivas, intelectuais e psicomotoras na realização da ação (GRECO; FERREIRA FILHO; SOUZA, 2000, p.123-124).

A partir da identificação dos fatores inerentes ao desenvolvimento da tática coletiva nos JEC, o ensino das capacidades perceptivas, intelectuais e psicomotoras deve ocorrer de forma gradativa e contextualizada, cujo método adotado desperte no aprendiz a busca por soluções das situações-problema do jogo. Dessa forma:

[...] o problema do principiante se encontra não só na dificuldade de escolher uma ação que lhe permita resolver a situação de jogo, mas também ter tempo suficiente para calcular todas as variáveis que a situação impõe, e ainda resolver a tempo a situação/ problema (GRECO, 1998, p.50).

Os deslocamentos em direções aleatórias e complexas, a interpretação das ações e deslocamentos dos jogadores, o gasto de energia adequado para cada tarefa e o domínio das emoções diante de erros e resultados, são exigências técnico-táticas dos JEC. Essas exigências ocorrem de forma imprevisível, por se tratar de um contexto complexo e dinâmico no qual os jogadores desenvolvem suas ações simultaneamente em diferentes locais do terreno de jogo.

Diante dessa perspectiva, por vezes, o aprendiz é submetido a treinamentos nos quais não pode expressar sua criatividade, devido à escolha de parâmetros (ou padrões) indissociáveis por parte do professor ou treinador. Para Baker (2003), os estímulos diversificados nas etapas iniciais de aprendizagem são apresentados como uma "rota alternativa" para o rendimento em alto nível. Faria e Tavares (1996, p.34) apontam que o professor ou treinador deve evitar "transformar o treino numa mera gestão de processologias técnicas e táticas limitadoras da criação dos pressupostos para a autonomia do jogador em ação".

Tavares (1996) aponta que os erros táticos geralmente ocorrem em mudanças repentinas do contexto do jogo, pois o aprendiz pode não estar preparado para adaptar-se e responder adequadamente 
aos fatores imprevisíveis. É necessário, então, confrontar o aprendiz com um contexto em que a análise subjetiva da situação-problema reflita certezas não tão certas e que:

[...] as influências da subjetividade em relação à análise da situação [permitam], a partir de expressões como 'depende' e 'talvez', demonstrar o entendimento que o jogador tem do cenário técnicotático e das suas possibilidades de intervenção (MENEZES, 2012, p.38).

Para o desenvolvimento das capacidades de compreensão e resolução de problemas táticos, Bayer (1994) sugere uma teoria de ensino dos JEC que pressupõe uma lógica comum entre eles. Assim sendo, bastaria ao jogador compreender alguns princípios operacionais e aplicar as regras de ação de uma modalidade esportiva para aprender a jogar outras, processo definido pelo autor como transfert. Dessa forma, são apresentadas similaridades entre os JEC, configurados por elementos invariantes como: a bola ou implemento central; o terreno demarcado; os alvos; os parceiros; os adversários; e as regras do jogo.

Para a concepção das ações táticas do jogo (individuais e coletivas), Bayer (1994) apresenta princípios operacionais referentes à fase ofensiva (conservar a bola, progredir em direção ao alvo e atacar o alvo) e defensiva (recuperar a posse da bola, impedir a progressão dos adversários e proteger o alvo), que dão sentido ao jogo e formam sua lógica central (MICHELINI et al., 2012). Ainda segundo Bayer (1994), o conhecimento tático do jogador é definido a partir de tais princípios básicos para o aprimoramento da capacidade de jogo de forma autônoma e da adequação às exigências de diferentes situações-problema encontradas. Assim, o processo de EAT poderia ser composto não apenas pela sistematização de ações próprias de uma função ou situação específica de um JEC, mas por amplas vivências, proporcionadas por práticas diferenciadas, baseadas nos princípios operacionais dos JEC.

Ainda assim, é possível encontrar especificidades nos diferentes JEC, que se expressam diferentemente, de acordo com o cenário técnico-tático do jogo. As regras de ação (ou formas com as quais 
os jogadores concebem e aplicam os princípios operacionais) seriam as adaptações desses princípios às situações-problema específicas dos JEC ao longo de sua prática (MICHELINI et al., 2012). Os diferentes JCI, por exemplo, apresentam regras de ação similares que possibilitam o transfert.

\section{A ESPECIALIZAÇÃo ESPORTIVA PRECOCE E OS MÉTOdOS DE ENSINO dOS JEC}

Por não respeitar algumas características da fase maturacional dos praticantes, a ocorrência de EEP pode desencadear o processo de abandono da prática ou até dificultar o êxito esportivo após a puberdade (NUNOMURA; PIRES; CARRARA, 2009). Balbino (2001) aponta que a condução adequada do processo de treinamento no esporte para crianças e jovens pode trazer importantes benefícios, principalmente diante de estímulos qualitativamente suficientes em um ambiente adequado.

Os professores e os treinadores são responsáveis por proteger a criança no período de iniciação esportiva, proporcionando-lhe experiências positivas para prolongar sua participação no esporte, visto que o principal objetivo desse processo na infância não é formar campeões (NUNOMURA; CARRARA; TSUKAMOTO, 2010). Porém, em muitos casos, treinadores sofrem pressões por parte das instituições em que trabalham para produzirem resultados competitivos precocemente (NUNOMURA; PIRES; CARRARA, 2009). Nota-se, nesta relação, que, mesmo que o professor ou treinador tenha convicções estruturadas frente a processos que evitem a EEP, por muitas vezes, tais abordagens podem ser suprimidas por dois movimentos sociais complexos: a) a distância entre a produção acadêmica em Educação Física e esporte e os ambientes de intervenção prática; e b) a falta de conhecimento específico sobre a área de atuação em Educação Física e esporte por parte de dirigentes e gestores, que podem exercer certa coerção sobre professores e treinadores.

Cavichiolli et al. (2011) apontam que existe uma crença entre 
treinadores e pais de jovens atletas de que, quanto mais cedo o talento esportivo for desenvolvido, maiores serão as chances de sucesso no alto desempenho. Essa crença faz com que determinadas etapas da formação de aprendizes sejam perdidas ou, na pior das situações, sejam desconhecidas por alguns treinadores. Sendo assim não deve se pretender que um jogador, durante a sua formação e descoberta de suas possibilidades individuais, seja apenas uma peça de uma engrenagem de um sistema de jogo fechado (LASIERRA; PONZ; ANDRÉS, 2005).

Dessa maneira, a busca pelo alto desempenho nas etapas iniciais de aprendizagem está relacionada com o tratamento dado pelos professores ou treinadores aos aprendizes, que são vistos como "miniaturização de adultos" e têm seus processos de crescimento, desenvolvimento e maturação tratados em segundo plano. Corrobora-se, portanto, com a afirmação de que "restam ainda motivos para continuarmos a acreditar que a cultura infantil está longe de ser uma simples cópia do modelo adulto ou dos artifícios da indústria de comunicações" (FREIRE, 1994, p.112), tornando necessária, portanto, uma completa adequabilidade das situações e atividades para garantir o acesso de crianças e adolescentes a um modelo de EAT que respeite as potencialidades, limites e expectativas dos aprendizes na prática esportiva.

A partir das definições de EEP apresentadas (BARBANTI, 2003; KUNZ, 1994; MOESCH et al., 2011), entendemos que esse processo baseia-se em duas características principais: exposição de crianças a processos de treinamento e competição prematuros, similares ao de atletas adultos; e especialização dos jogadores em modalidades e funções específicas, restringindo suas possibilidades de ampliação do repertório motor e compreensão tática.

Quanto ao primeiro fator, diz respeito à forma com que o professor ou treinador concebe e conduz o processo de EAT, expondo ou não seus aprendizes a situações apropriadas às suas capacidades e características. Quanto ao segundo componente da EEP, pode-se estabelecer uma relação íntima entre o método de EAT utilizado e as possibilidades de aprendizagens diversificadas apresentadas aos 
aprendizes, no mesmo ou entre diferentes JEC. Como exemplo, podese apontar a utilização de um jogo no qual a bola é controlada com as mãos para aprendizes no futebol, enquanto em um processo de EAT do handebol, a utilização dos pés para contato com a bola também pode ser interessante, desde que ambas as situações contemplem os princípios operacionais em comum entre os JCI e haja o transfert proposto por Bayer (1994).

Os processos que privilegiam as repetições de movimentos e/ ou as ações táticas específicas e estereotipadas podem contribuir para a ocorrência de EEP, principalmente se estiverem associados a um quadro de treinamento e competição similar ao universo adulto. Essa situação exige cuidados por parte do professor ou treinador, pois restringe as possibilidades de aprendizagem diversificada de elementos técnico-táticos.

Por outro lado, destacamos que a simples utilização de métodos de ensino que abarcam vivências diversificadas também não preveniria a não ocorrência da EEP, mas essa diversificação deve ser vista como uma alternativa à iniciação esportiva (BAKER, 2003). Tal medida atende ao segundo fator destacado anteriormente, mas que precisa estar associado a um processo de EAT que respeite a fase de maturação e a capacidade de interação cognitiva e social da criança, de modo a não tratá-la como um adulto em miniatura, mas como um aprendiz que lida com o esporte principalmente pela via da ludicidade e da formação moral e motora.

Nesse cenário, tem-se que o princípio global-funcional sugere um processo de EAT amplo, que considera a complexidade dos JCI e o encadeamento entre os elementos técnicos e as situaçõesproblema. Assim, esse princípio é relevante como forma de ampliar as vivências diversificadas, principalmente por privilegiar o aprendizado dos princípios operacionais e facilitar o transfert. Por outro lado, tem-se menor possibilidade de ação nesse sentido quando o princípio analítico-sintético é aplicado, visto que esse prioriza a execução motora baseada em modelos estereotipados e até em função específica desempenhada pelo jogador dentro de uma única modalidade. 
O método situacional com processos cognitivos privilegia os mesmos objetivos e objetos do princípio global-funcional, porém pautase na fragmentação do jogo em situações específicas. Essa fragmentação demanda, por parte do responsável pela atividade, grande diversificação dos cenários propostos, de modo a proporcionar vivências variadas aos aprendizes e evitar certa especialização em uma determinada situação (como o 2x2) ou modalidade específica.

\section{Considerações finals}

Independente do ambiente físico e da disponibilidade de materiais para o ensino dos JEC, é necessário enfatizar os diferentes aspectos do desenvolvimento (motores, cognitivos e sócio-afetivos). Diversas estratégias podem ser aplicadas ao longo do processo de EAT, como os jogos reduzidos e adaptados, as situações de jogo, ou mesmo a abordagem centrada na técnica de vários esportes.

Quando nos reportamos à iniciação esportiva, devemos considerar a fase na qual o aprendiz se encontra e também viabilizar o ensino dos conteúdos da modalidade a partir de jogos e brincadeiras que motivem a sua continuidade no esporte.

Utilizar os diferentes princípios metodológicos, com base no transfert entre os JCI, pode significar uma oportunidade para ampliar o repertório motor e cognitivo dos aprendizes e de facilitar a compreensão e a solução de situações-problema e da possibilidade de aplicar a capacidade de jogo em diferentes contextos esportivos. Assim, as experiências em diversos JCI, proporcionadas pelos diferentes métodos de EAT, poderiam minimizar a EEP, ao menos em relação ao desenvolvimento da capacidade de jogo.

Por meio da diversidade de vivências os professores e treinadores oferecem oportunidades para que os aprendizes percebam diferentes elementos, seja em uma situação de jogo, em um jogo reduzido ou na execução de um determinado movimento. A forma com que o professor ou treinador lida com os procedimentos didáticos de diferentes métodos de ensino dos JEC pode configurar 
um ambiente de EEP. Essas vivências devem ser apresentadas de diferentes formas, de modo a oferecer aos aprendizes um maior repertório de habilidades motoras e cognitivas para atenderem às necessidades impostas pelo jogo.

Greco (2001) aponta que o ensino de um JEC deve ser promovido a partir de uma metodologia mista, que contemple as mais diferentes situações (técnico-táticas) apresentadas pelo jogo. Corroborando o autor supracitado, García Herrero (2003) relata que talvez não seja possível ensinar todos os diferentes conteúdos seguindo a mesma teoria de aprendizagem. Isso ocorre, pois a natureza das habilidades indica o contrário, como a marcação e o controle de um oponente e as situações reduzidas de jogo (3x3, 4x4, 6x5 etc.).

Com base nas características individuais e na etapa do processo de EAT aos quais os aprendizes estão inseridos, há necessidade de uma pedagogia dos JEC que permita uma participação ampla e duradoura desses em atividades esportivas, com vistas a evitar a EEP em qualquer modalidade.

Sendo assim, entendemos que a iniciação esportiva deva conduzir os aprendizes ao desenvolvimento de formas flexíveis na resolução de situações-problema que lhes são apresentadas. Cabe ao professor ou treinador selecionar, em cada etapa do processo de EAT, o método mais eficaz para atender aos objetivos dos aprendizes e da equipe, de forma que esses sejam capazes de tomar as decisões com criticidade e criatividade que atendam às demandas do contexto dos JEC. 
Early sport specialization and the teaching of invasion games

Abstract: The aim of this study was to establish a relationship between different methodological principles of invasion games (IG) teaching and the early sports specialization process (ESS). We consider ESS as an imposition on children, regarding competition and training procedures, able for adults, and limited and specific motor experiences. We conclude that, although the teaching of IG, has no direct influence over the competitive process in initiation stage, it must be diversified methods and grounded on different sports. Thus, it may be a component that would avoid stereotyped behaviors in the of sport initiation, therefore, hindering the ESS.

Keywords: Sports. Specialization. Early intervention.

\section{Especialización deportiva precoz y la enseñanza} de los deportes colectivos de invasión

Resumen: El objetivo de este trabajo fue establecer una relación entre los diferentes principios metodológicos de la enseñanza de los deportes de equipo de invasión (DEI) y los procesos de especialización deportiva precoz (EDP). EDP es un fenómeno de imposición, a los niños, de los planes de competición y entrenamiento adecuados para los adultos y la especificidad y limitación de las experiencias motoras. Basado en la literatura, se concluyó que la enseñanza de los $\mathrm{DEl}$, a pesar de no estar directamente influenciada por los procesos competitivos en la iniciación, puede ser basada en métodos diversificados y en diferentes deportes, dificultando el EEP.

Palabras-clave: deportes. Especialización. Intervención precoz. 


\section{REFERÊNCIAS}

BAKER, Joseph. Early Specialization in Youth Sport: a requirement for adult expertise? High Ability Studies, London, v. 14, n. 1, p. 85-94, 2003.

BALBINO, Hermes Ferreira. Jogos desportivos coletivos e os estímulos das inteligências múltiplas: bases para uma proposta em pedagogia do esporte. 2001. 142 f. Dissertação (Mestrado em Educação Física) - Faculdade de Educação Física, Universidade Estadual de Campinas, Campinas, 2001.

BARBANTI, Valdir José. Dicionário de educação física e esporte. 2. ed. Barueri: Manole, 2003.

BAYER, Claude. O ensino dos desportos colectivos. Lisboa: Dinalivros, 1994.

CAVICHIOLLI, Fernando Renato et al. O processo de formação do atleta de futsal e futebol: análise etnográfica. Revista Brasileira de Educação Física e Esporte, São Paulo, v. 25, n. 4, p. 631-647, 2011.

COAKLEY, J. Sports in society: issues and controversies. 10. ed. Saint Louis: Times Mirror, 2008.

DAOLIO, Jocimar; MARQUES, Renato Francisco Rodrigues. Relato de uma experiência de ensino do futsal para crianças de 9 a 12 anos. Motriz, Rio Claro, v. 9, n. 3, p. 169-174, 2003.

DARIO, Bruno Estevan Siqueira; BARQUILHA, Gustavo; MARQUES, Reinaldo Monteiro. Lesões esportivas: um estudo com atletas do basquetebol bauruense. Revista Brasileira de Ciências do Esporte, Florianópolis, v. 31, n. 3, p. 205215, 2010.

DIETRICH, Knut; DÜRRWÄCHTER, Gerhard; SCHALLER, Hans-Jürgen. Os grandes jogos: metodologia e prática. Rio de Janeiro: Ao livro técnico, 1984.

FARIA, Rui; TAVARES, Fernando. O comportamento estratégico. Acerca da autonomia de decisão nos jogadores de desportos colectivos. In: ESTRATÉGIA e táctica nos jogos desportivos colectivos. Porto: Centro de Estudos dos Jogos Desportivos, Universidade do Porto, 1996. p. 33-38.

FREIRE, João Batista. Educação de corpo inteiro: teoria e prática da educação física. 4. ed. São Paulo: Scipione, 1994.

FREIRE, João Batista. Pedagogia do futebol. 2. ed. Campinas: Autores Associados, 2006.

GALATTI, Larissa Rafaela et al. Pedagogia do esporte: procedimentos pedagógicos aplicados aos jogos esportivos coletivos. Conexões, Campinas, v. 6, especial, p. 397-408, 2008. 
GALATTI, Larissa Rafaela; PAES, Roberto Rodrigues. Pedagogia do esporte e a aplicação das teorias acerca dos jogos esportivos coletivos em escolas de esportes: o caso de um clube privado de Campinas-SP. Conexões, Campinas, v. 5, n. 2, p. 31-44, 2007.

GARCÍA HERRERO, Juan Antonio. Entrenamiento en balonmano: bases para la construcción de un proyecto de formación defensiva. Barcelona: Paidotribo, 2003.

GARGANTA, J. Para uma teoria dos jogos desportivos colectivos. In: GRAÇA, A.; OLIVEIRA, J. (Org.). 0 ensino dos jogos deportivos. 3. ed. Porto: Universidade do Porto, 1998. p. 11-26.

GRAÇA, Amândio Braga dos Santos; MESQUITA, Isabel Maria Ribeiro. A investigação sobre o ensino dos jogos desportivos: ensinar e aprender as habilidades básicas do jogo. Revista Portuguesa de Ciências do Desporto, Porto, v. 2, n. 5, p. 6779, 2002.

GRAÇA, Amândio Braga dos Santos; MESQUITA, Isabel Maria Ribeiro. A investigação sobre os modelos de ensino dos jogos desportivos. Revista Portuguesa de Ciência do Desporto, Porto, v. 7, n. 3, p. 401-421, 2007.

GRECO, Pablo Juan. La formación del jugador inteligente. Revista Stadium, Buenos Aires, v. 22, n. 128, p. 22-31, 1988.

GRECO, Pablo Juan (Org.). Iniciação esportiva universal: metodologia da iniciação na escola e no clube. Belo Horizonte: Ed. UFMG, 1998. v. 2.

GRECO, Pablo Juan. Métodos de ensino-aprendizagem-treinamento nos jogos esportivos coletivos. In: GARCIA, E.S.; LEMOS, K.L.M. Temas Atuais VI em Educação Física e Esportes. Belo Horizonte: Saúde, 2001. p. 48-72.

GRECO, Pablo Juan; FERREIRA FILHO, Eloi; SOUZA, Pablo Ramón Coelho de. Avaliação do comportamento tático no handebol. In: GRECO, P.J. (Org.). Caderno de rendimento do atleta de handebol. Belo Horizonte: Health, 2000. p. 121134.

HASTIE, Peter A.; CURTNER-SMITH, Matthew D. Influence of a hybrid Sport Education - Teaching Games for Understanding unit on one teacher and his students. Physical Education and Sport Pedagogy, London, v. 11, n. 1, p. 1-27, 2006.

KNIJNIK, Jorge Dorfman; MASSA, Marcelo; FERRETTI, Marco Antônio de Carvalho. Direitos Humanos e Especialização Esportiva Precoce: Considerações Metodológicas e Filosóficas. In: MACHADO, Afonso Antonio (Org.). Especialização esportiva precoce: perspectivas atuais da psicologia do esporte. Jundiaí: Fontoura, 2008. p. 109-128.

KUNZ, Elenor. Transformação didático-pedagógica do esporte. ljuí: Unijuí, 1994.

LASIERRA, Gerard; PONZ, José María; ANDRÉS, Fernando de. 1013 ejercicios y juegos aplicados al balonmano. 4. ed. Barcelona: Paidotribo, 2005. v. 1. 
MARQUES, Antonio A. Desporto e futuro: o futuro do desporto. In: HORIZONTES e órbitas nos treinos dos jogos desportivos. Porto: Universidade do Porto, 2000. p. 720.

MARQUES, Renato Francisco Rodrigues; ALMEIDA, Marco Antônio Bettine de; GUTIERREZ, Gustavo Luis. Esporte: um fenômeno heterogêneo: estudo sobre o esporte e suas manifestações na sociedade contemporânea. Movimento, Porto Alegre, v. 13, p. 225-242, 2007.

MASSA, Marcelo; UEZU, Rudney; BÖHME, Maria Tereza Silveira. Judocas olímpicos brasileiros: fatores de apoio psicossocial para o desenvolvimento do talento esportivo. Revista de Brasileira de Educação Física e Esporte, São Paulo, v. 24, n. 4, p. 471-481, 2010.

MEMMERT, Daniel; HARVEY, Stephen. Identification of non-specific tactical tasks in invasion games. Physical Education and Sport Pedagogy, London, v. 15, n. 3, p. 287-305, 2010.

MENEZES, Rafael Pombo. O ensino dos sistemas defensivos do handebol: considerações acerca da categoria cadete. Pensar a Prática, Goiânia, v.13, n.1, p.1-16, 2010.

MENEZES, Rafael Pombo. Contribuições da concepção dos fenômenos complexos para o ensino dos esportes coletivos. Motriz, Rio Claro, v. 18, n. 1, p. 34-41, 2012.

MENEZES, Rafael Pombo; SOUSA, Maria Suélia dos Santos; BRAGA, José Werley Carvalho. Processo de ensino-aprendizagem-treinamento de handebol para a categoria mirim em instituições não-formais de ensino: concepções e metodologias. Conexões, Campinas, v. 9, n. 2, p. 49-69, 2011.

MICHELINI, Marcelo Campagno et al. Futsal: tática defensiva contemporânea e a teoria de ensino dos jogos esportivos coletivos de Claude Bayer. Conexões, Campinas, v. 10, n. 1, p. 20-37, 2012.

MOESCH, K. et al. Late specialization: the key to success in centimeters, grams, or seconds (cgs) sports. Scandinavian Journal Medicine of Science Sports, Copenhagen, v. 21, p. 282-290, 2011.

MÜLLER, Manfred et al. Balonmano entrenarse jugando: el sistema de ejercicios completo. Barcelona: Paidotribo, 1996.

NUNOMURA, Myrian; CARRARA, Paulo Daniel Sabino; TSUKAMOTO, Mariana Harumi Cruz. Ginástica artística e especialização precoce: cedo demais para especializar, tarde demais para ser campeão! Revista de Brasileira de Educação Física e Esporte, São Paulo, v. 24, n. 3, p. 305-14, 2010.

NUNOMURA, Myrian; PIRES, Fernanda Regina; CARRARA, Paulo. Análise do treinamento na ginástica artística brasileira. Revista de Brasileira de Educação Física e Esporte, São Paulo, v. 31, n. 1, p. 25-40, 2009. 
PAES, Roberto Rodrigues. Educação física escolar: o esporte como conteúdo pedagógico no ensino fundamental. Canoas: Ed. ULBRA, 2001.

PAULA, Paula Figueiredo Ângela de; GRECO, Pablo Juan; SOUZA, Pablo Ramón Coelho de. Tática e processos cognitivos subjacentes à tomada de decisão nos jogos esportivos coletivos. In: GARCIA, E.S.; LEMOS, K.L.M. Temas Atuais V em Educação Física e Esportes. Belo Horizonte: Saúde, 2000. p.11-27.

RAMOS, Adamilton Mendes; NEVES, Ricardo Lira Rezende. A iniciação esportiva e a especialização precoce à luz da teoria da complexidade-notas introdutórias. Pensar a Prática, Goiânia, v. 11, n. 1, p. 1-8, 2008.

REVERDITO, Riller Silva; SCAGLIA, Alcides. Pedagogia do esporte: jogos coletivos de invasão. São Paulo: Phorte, 2009.

RICCI, Giuliano Salera et al. Avaliação da aprendizagem do handebol por jovens entre 11 e 14 anos a partir do método situacional. Pensar a Prática, Goiânia, v. 14, n. 1, p. 1-18, 2011.

SANTANA, Wilton Carlos de. Futsal: apontamentos pedagógicos na iniciação e na especialização. Campinas: Autores Associados, 2004.

SANTANA, Wilton Carlos de. Pedagogia do esporte na infância e complexidade. In: PAES, R.R.; BALBINO, H.F. Pedagogia do esporte: contextos e perspectivas. Rio de Janeiro: Guanabara Koogan, 2005. p. 1-22.

SCHMIDT, Richard A.; WRISBERG, Craig. A. Aprendizagem e performance motora: uma abordagem da aprendizagem baseada no problema. Porto Alegre: Artmed, 2001.

TAVARES, Fernando. Bases teóricas da componente táctica nos jogos desportivos colectivos. In: OLIVEIRA, José; TAVARES, Fernando. (editores). Estratégia e Táctica nos Jogos Desportivos Colectivos. Porto: Universidade do Porto, 1996. p. 25-32.

UGRINOWITSCH, Herbert; DANTAS, Luiz E.P.B.T. Efeito do estabelecimento de metas na aprendizagem do arremesso do Basquetebol. Revista Portuguesa de Ciências do Desporto, Porto, v. 2, n. 5, p. 58-63, 2002.

\author{
Endereço para correspondência: \\ Universidade de São Paulo \\ Escola de Educação Física e Esporte de Ribeirão Preto \\ Av. Bandeirantes, 3900 - Monte Alegre \\ Ribeirão Preto/SP \\ CEP: $14040-907$ \\ E-mail: rafaelpombo@usp.br
}

Recebido em: 28-05-2013

Aprovado em: 2.12 .1013

Movimento, Porto Alegre, v. 20, n. 01, p. 351-373, jan/mar de 2014. 